Sharif University of Technology
Scientia Iranica
SCIENTIA
I RAN I CA
http://scientiairanica.sharif.edu

Invited Paper

\title{
Effect of creep on high-order shear deformable beams
}

\author{
M. Ghabdian ${ }^{\mathrm{a}, *}$, S.B. Beheshti Aval ${ }^{\mathrm{a}}$, and A. Vafai ${ }^{\mathrm{b}}$ \\ a. Department of Civil Engineering, K. N. Toosi University of Technology, Tehran, Iran. \\ b. Department of Civil Engineering, Sharif University of Technology, Tehran, Iran. \\ Received 21 February 2019; accepted 11 March 2019
}

\author{
KEYWORDS \\ Creep; \\ Concrete beam; \\ Strain distribution; \\ Shear deformable \\ beam; \\ Kelvin chain model.
}

\begin{abstract}
A powerful and new theoretical approach is used to obtain an expression for the effect of creep on reinforced concrete shear deformable beams. First, a method is proposed for Euler-Bernoulli beam to analyze the long-term behavior of concrete beams based on linear strain theory. Second, a formulation has been developed to analyze the strain distribution in shear deformable concrete beams. Finally, three numerical examples are included in order to compare well-known codes with the proposed method. The comparison of the proposed method, FEM, codes, and experimental works demonstrates that the proposed analytical procedure can effectively simulate creep behavior of reinforced concrete beams.
\end{abstract}

(C) 2019 Sharif University of Technology. All rights reserved.

\section{Introduction}

In view of the mechanical behavior of beams, three various beam theories, namely Euler-Bernoulli beam theory, Timoshenko beam theory, and higher-order beam theory, are considered [1]. Figure 1 shows the cross-section displacement in different beam theories. In the case of simple and classic Euler-Bernoulli beam theory, it is assumed that the plane sections of the cross-section remain plane and normal to the mid-plane after deformation. In Euler-Bernoulli beam theory, since transverse shear and transverse normal strains are not taken into account, this theory is widely applied to analyze shallow concrete beams. In the case of deep concrete beams due to the significance of shear effects, a more accurate concept such as Timoshenko beam theory is normally used. In Timoshenko beam

\footnotetext{
*. Corresponding author.

E-mail addresses: mghabdian@mail.kntu.ac.ir (M. Ghabdian); beheshti@kntu.ac.ir (S.B. Beheshti Aval); vafai@sharif.edu (A.Vafai)
}

doi: $10.24200 /$ sci. 2019.21359 theory with a highly accurate beam modeling, the beam cross-section remains plane; however, a shear correction factor is defined in order to include the effect of shear deformation and compensate the error due to constant shear stress assumption. The limitations of shear coefficient-based theory recognize the need for a more accurate higher-order beam theory with transverse inextensibility. Various studies based on higher-order beam theories have been presented in the literature. Some models based on variation of shear strain and shear stress along the height of the beam are proposed [2-6].

In order to include the warping of the crosssections through a finite element framework, the higher-order shear-deformable models were developed in other research works [7-13]. In these models, the third-order theory produces a slight increase in accuracy. However, for the sake of generalization, to reinforce the concrete section, a more effective and feasible method is required. Undoubtedly, in previous studies, effects of aging and time-dependent parameters, such as the effect of creep on behavior of high-order shear deformable concrete deep beams, were not taken into account. This need has initiated a mathematical effort 

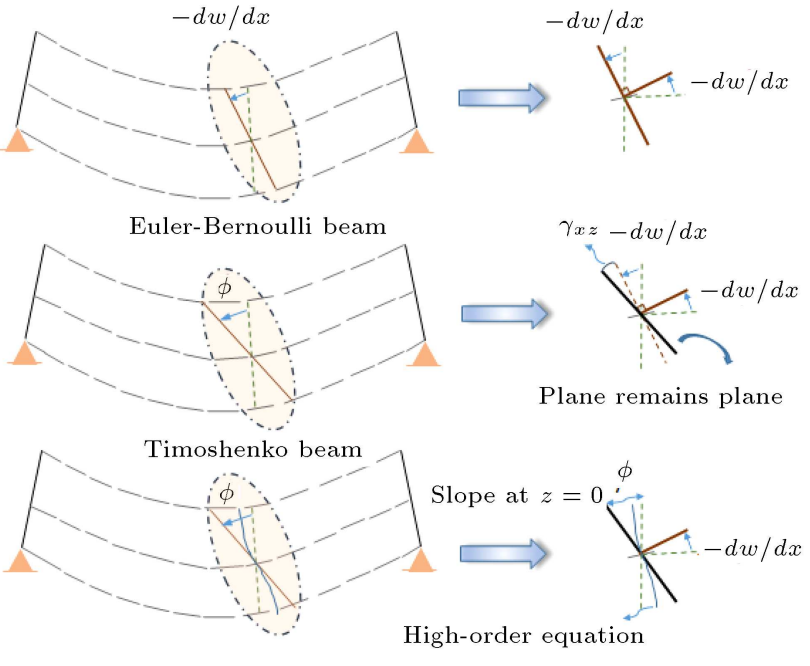

Reddy-Bickford beam

Figure 1. Deformation of cross-section in various beam theories.

in order to model RC beams in which both creep and strain nonlinearity are considered. In addition, many authors have proposed effective models in practical codes such as ACI-209, fib model code 2010, and model B3 for calculating the long-term behavior of concrete structures [14-18]. In all models, displacement field of the element is calculated by using Euler-Bernoulli beam theory, and non-proportional strain distribution along the section height is not taken into account, particularly in the case of concrete beams. In contrast to RC shallow beams, deflection of deep concrete beams is profoundly influenced by strain nonlinearity in sections. Thus, the need to solve this problem by a new method based on a mathematical approach has been established.

To the best of this author's knowledge, the higherorder beam model considering time effects such as creep has not yet been addressed. In this paper, a new approach is applied to a shear deformable highorder beam, including additional deflection due to creep. The objective of this study is to develop a powerful analytical model for the prediction of longtime deflection of shear sensitive elements such as RC deep beams due to creep under sustained loading.
Experimental results are used to verify the proposed analytical approach.

\section{Model formulation}

Due to creep and shrinkage of concrete, strain significantly increases in this section, and curvature increases with time. The magnitude of strain in time $\varepsilon(t)$ is the sum of free shrinkage strain $\varepsilon_{s h}\left(\tau_{k}\right)$, unrestrained creep strain caused by the initial concrete strain, $\varepsilon_{c r, k}=$ $\phi\left(\tau_{k}, \tau_{0}\right) \sigma_{c, 0} / E_{c, 0}$, and creep and elastic strain caused by gradual changes in force [19].

Based on the similarity of the triangles shown in Figure 2, it is recommended for authors to use the following relation to distribute strain in a concrete section:

$$
f(z)=-\frac{\varepsilon_{c}}{c}\left(z-\frac{h}{2}+c\right)=-\varepsilon_{c}\left(\frac{z}{c}-\frac{h}{2 c}+1\right),
$$

where $\varepsilon_{c}$ is the maximum strain in the concrete section.

To describe the property of strain diagram, it is necessary to specify parameters $n$ and $m$.

Consider the effect of creep on strain distribution as follows:

$$
f^{\prime}(z)=n f(z)+m=\frac{-n \varepsilon_{c}}{c}\left(z-\frac{h}{2}+c\right)+m .
$$

Further, parameter $n$ can be formulated as follows:

$$
n=\frac{\frac{\varepsilon_{c}^{\prime}}{c^{\prime}}}{\frac{\varepsilon_{c}}{c}}=\frac{\varepsilon_{c}^{\prime} \times c}{\varepsilon_{c} \times c^{\prime}} .
$$

In addition, based on the gradual development of creep strain in the concrete section, strain in compression zone of concrete can be defined as follows [20]:

$$
\varepsilon_{c}^{\prime}=\varepsilon_{c}(1+\alpha \varphi),
$$

where $\varphi$ is the creep coefficient.

For a simply supported RC beam, as shown in Figure 3, strain state in sections is calculated considering instantaneous strain and creep-induced strain.

In order to evaluate coefficient " $\alpha$ " as shown in Figure 3, some simply supported RC beams with

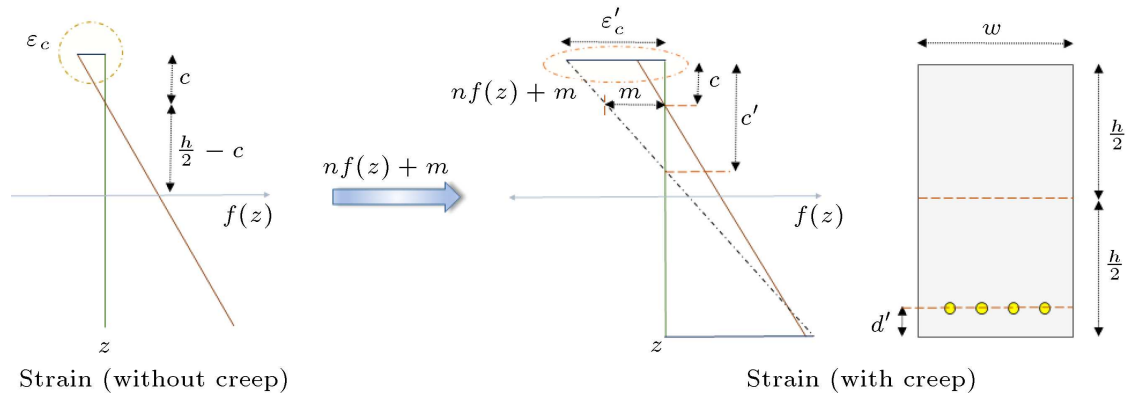

Figure 2. Cross-sectional strain distribution for Euler-Bernoulli element. 


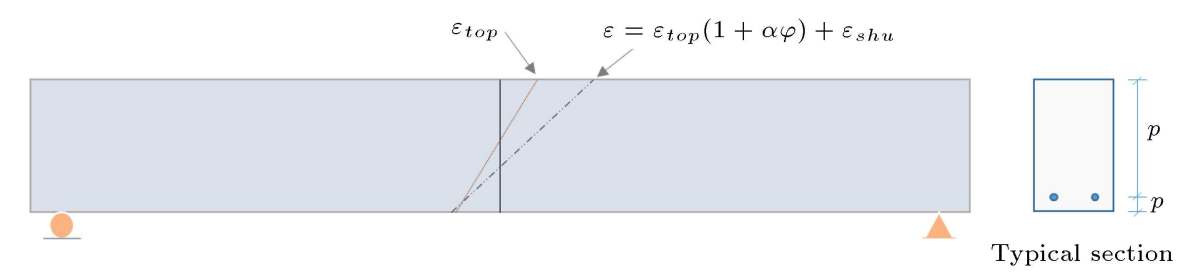

Figure 3. Effect of creep and shrinkage on the strain distribution of RC beams.

Table 1. Range of parameter $\alpha$ for simply supported beams.

\begin{tabular}{|c|c|c|}
\hline Beam no. & Creep coefficient & $\alpha$ \\
\hline 1 & 2.5 & 0.49 \\
\hline 2 & 1.7 & 0.43 \\
\hline 3 & 3.2 & 0.52 \\
\hline 4 & 4.1 & 0.55 \\
\hline 5 & 3 & 0.5 \\
\hline 6 & 2 & 0.46 \\
\hline 7 & 1.5 & 0.42 \\
\hline 8 & 4.5 & 0.56 \\
\hline 9 & 5 & 0.62 \\
\hline 10 & 3.5 & 0.52 \\
\hline 11 & 3.8 & 0.54 \\
\hline 12 & 2.4 & 0.48 \\
\hline 13 & 2.3 & 0.48 \\
\hline 14 & 4.8 & 0.59 \\
\hline 15 & 4.9 & 0.6 \\
\hline 16 & 1.6 & 0.42 \\
\hline 17 & 1.9 & 0.45 \\
\hline 18 & 1.8 & 0.44 \\
\hline 19 & 1.55 & 0.4 \\
\hline 20 & 1.85 & 0.45 \\
\hline 21 & 2.15 & 0.47 \\
\hline 22 & 2.35 & 0.48 \\
\hline 23 & 2.85 & 0.5 \\
\hline 24 & 4.35 & 0.57 \\
\hline 25 & 4.85 & 0.59 \\
\hline 26 & 3.35 & 0.51 \\
\hline 27 & 4.25 & 0.55 \\
\hline 28 & 3.55 & 0.52 \\
\hline 29 & 4.65 & 0.56 \\
\hline \multirow[t]{2}{*}{30} & 2.95 & 0.5 \\
\hline & Average & 0.505667 \\
\hline
\end{tabular}

a fully-cracked cross-section were analyzed by AgeAdjusted Effective Modulus Method (AEMM). Table 1 presents the numerical results of estimating " $\alpha$ ".

Age-adjusted effective modulus is defined by Bazant [21]:

$$
\bar{E}_{e}\left(t, \tau_{0}\right)=\frac{E_{c}\left(\tau_{0}\right)}{1+\chi\left(t, \tau_{0}\right) \varphi\left(t, \tau_{0}\right)},
$$

where $E_{c}\left(\tau_{0}\right)$ is the concrete modulus at time $\tau_{0}$ (age at first loading $), \varphi\left(t, \tau_{0}\right)$ and $\chi\left(t, \tau_{0}\right)$ are the creep and aging coefficients at time $t$ for concrete loaded at $\tau_{0}$, respectively. The last one is expressed as follows [21]:

$$
\chi\left(t, \tau_{0}\right)=\frac{E_{C}\left(\tau_{0}\right)}{E_{C}\left(\tau_{0}\right)-R\left(t, \tau_{0}\right)}-\frac{1}{\varphi\left(t, \tau_{0}\right)},
$$

where $R\left(t, \tau_{0}\right)$ is the relaxation function. Relaxation is defined as the stress at time $t$ when a constant (unit) strain is applied to the sample at time $\tau_{0}$.

In addition, the age-adjusted creep factor can be expressed as follows:

$$
\bar{F}_{e, 0}=\frac{\varphi\left(t, \tau_{0}\right)\left[\chi\left(t, \tau_{0}\right)-1\right]}{1+\chi\left(t, \tau_{0}\right) \varphi\left(t, \tau_{0}\right)} .
$$

According to AEMM, axial force and moment resisted by the concrete part of the cross-section at time $\tau_{0}$ are:

$$
\begin{aligned}
& N_{c, 0}=A_{c} E_{c, 0} \varepsilon_{r, 0}+B_{c} E_{c, 0} \kappa_{0}, \\
& M_{c, 0}=B_{c} E_{c, 0} \varepsilon_{r, 0}+I_{c} E_{c, 0} \kappa_{0},
\end{aligned}
$$

where $A_{c}, B_{c}$, and $I_{c}$ are the area, the first moment, and the second moment of concrete parts of the crosssection, respectively. $\kappa_{0}$ is the curvature at time $\tau_{0}$, and $\varepsilon_{r, 0}$ is the strain at reference axis at time $\tau_{0}$.

In addition, the cross-sectional rigidities $R_{A, k}$, $R_{B, k}$, and $R_{l, k}$ at time $\tau_{k}$ are given by:

$$
\begin{aligned}
& R_{A, k}=A_{c} \bar{E}_{e, k}+R_{A, s}, \\
& R_{B, k}=B_{c} \bar{E}_{e, k}+R_{B, s}, \\
& R_{I, k}=I_{c} \bar{E}_{e, k}+R_{I, s},
\end{aligned}
$$

where $R_{A, s}=A_{s} E_{s}$ (reinforcement rigidity), $R_{B, s}=$ $y_{s} A_{s} E_{s}$ (the first moment of reinforcing steel bar area of the cross-section), $R_{I, s}=y_{s}^{2} A_{s} E_{s}$ (the second moment of reinforcing steel bar area of the crosssection).

The relation between strain and internal actions on cross-sections can be defined by matrix $\mathbf{F}$ as follows:

$$
\mathbf{F}_{k}=\frac{1}{R_{A, k} R_{I, k}-R_{B, k}^{2}}\left[\begin{array}{cc}
R_{I, k} & -R_{B, k} \\
-R_{B, k} & R_{A, k}
\end{array}\right] .
$$


On the other hand, matrix $\mathbf{F}$ relates strain to internal forces at any desired time. To account for creep and shrinkage during previous time periods, matrix $\mathbf{f}$ is defined by:

$$
\begin{aligned}
\mathbf{f}_{c r, k} & =\bar{F}_{e, 0}\left[\begin{array}{l}
N_{c, 0} \\
M_{c, 0}
\end{array}\right], \\
\mathbf{f}_{s h, k} & =\left[\begin{array}{l}
A_{c} \\
B_{c}
\end{array}\right] \bar{E}_{e, k} \varepsilon_{s h, k} .
\end{aligned}
$$

In addition, the strain vector at concrete cross-sections is defined by:

$$
\varepsilon_{k}=\mathbf{F}_{k}\left(\mathbf{r}_{e, k}-\mathbf{f}_{c r, k}+\mathbf{f}_{s h, k}\right) .
$$

Strain at any depth of concrete cross-sections can be addressed as follows:

$$
\varepsilon_{k}=\varepsilon_{r, k}+y \kappa_{k} .
$$

These results are valid for Euler-Bernoulli beam element, and it is worth noting that mid-span deflection can be addressed for statically determinate beams as in the following [19]:

$$
v_{C}=\frac{l^{2}}{96}\left(\kappa_{A}+10 \kappa_{C}+\kappa_{B}\right),
$$

where $l$ is the beam length, and $\kappa_{A}, \kappa_{B}$, and $\kappa_{C}$ are the curvatures at any time at supports $A, B$, and mid-span point $C$, respectively.

As illustrated in Table 1, parameter $\alpha$ does not deviate significantly from a constant value of 0.5 ; therefore, this value can be assigned to strain in Eq. (4).

Based on Eq. (2), the parameter following the equation can be derived:

$$
f_{(h / 2)}^{\prime}=n f_{(h / 2)}+m
$$

where $f_{(h / 2)}^{\prime}$ is the strain at $z=\frac{h}{2}$ for the effect of creep in a concrete section. By assuming the strain equality of steel in both cases with and without creep, strain in steel may be described as follows:

$$
f_{\left(h / 2-d^{\prime}\right)}^{\prime}=f_{\left(h / 2-d^{\prime}\right)} \text {. }
$$

By substituting the relationship between $f_{(h / 2)}^{\prime}$ and $f_{(h / 2)}$ into Eq. (20), a new equation can be written in the following form:

$$
\begin{aligned}
& n f_{\left(h / 2-d^{\prime}\right)}+m=f_{\left(h / 2-d^{\prime}\right)}, \\
& m=f_{\left(h / 2-d^{\prime}\right)}(1-n)=\varepsilon_{s}(1-n) .
\end{aligned}
$$

Let the strain in Euler-Bernoulli beam be described by a simple relation as follows:

$$
\varepsilon_{s}=\frac{d-c}{c} \times \varepsilon_{c}
$$

$$
\varepsilon_{s}=\frac{d-c^{\prime}}{c^{\prime}} \times \varepsilon_{c}^{\prime}
$$

where $\varepsilon_{s}$ is the strain in the longitudinal reinforcement.

From Eqs. (23) and (24), it can be concluded that:

$$
\begin{aligned}
& \frac{d-c}{c} \times \varepsilon_{c}=\frac{d-c^{\prime}}{c^{\prime}} \times \varepsilon_{c}^{\prime}=\left(\frac{d}{c^{\prime}}-1\right) \times \varepsilon_{c}^{\prime}, \\
& \left(\frac{d}{c^{\prime}}-1\right) \times \varepsilon_{c}^{\prime}=\left(\frac{d}{c}-1\right) \times \varepsilon_{c}, \\
& \left(\frac{d}{c}-1\right) \times \frac{\varepsilon_{c}}{\varepsilon_{c}^{\prime}}=\frac{d}{c^{\prime}}-1, \\
& c^{\prime}=\frac{d}{\left(\frac{d}{c}-1\right) \times \frac{\varepsilon_{c}}{\varepsilon_{c}^{\prime}}+1}, \\
& n=\frac{\varepsilon_{c}^{\prime} \times c}{\varepsilon_{c} \times c^{\prime}}=\frac{\varepsilon_{c}^{\prime}}{\varepsilon_{c}} \times \frac{c}{d}\left[\left(\frac{d}{c}-1\right) \times \frac{\varepsilon_{c}}{\varepsilon_{c}^{\prime}}+1\right] .
\end{aligned}
$$

Finally, for strain-induced creep distribution in section, the following relation is proposed:

$$
\begin{aligned}
f^{\prime}(z)= & \frac{\varepsilon_{c}^{\prime}}{\varepsilon_{c}} \times \frac{c}{d}\left[\left(\frac{d}{c}-1\right) \times \frac{\varepsilon_{c}}{\varepsilon_{c}^{\prime}}+1\right] \times f(z) \\
& +\frac{d-c}{c} \varepsilon_{c} \times\left[1-\left(\frac{\varepsilon_{c}^{\prime}}{\varepsilon_{c}} \times \frac{c}{d}\left[\left(\frac{d}{c}-1\right)\right.\right.\right. \\
& \left.\left.\left.\times \frac{\varepsilon_{c}}{\varepsilon_{c}^{\prime}}+1\right]\right)\right] .
\end{aligned}
$$

Considering $\varepsilon_{c}^{\prime}=\varepsilon_{c}(1+\alpha \varphi)$, substituting Eq. (18) into (30), and selecting $\alpha=0.5$ for the final creep strain in fully cracked section strain, the following relation can be written as follows:

$$
\begin{aligned}
f^{\prime}(z)= & \frac{\varepsilon_{c}(1+0.5 \varphi)}{\varepsilon_{c}} \times \frac{c}{d}\left[\left(\frac{d}{c}-1\right)\right. \\
& \left.\times \frac{\varepsilon_{c}}{\varepsilon_{c}(1+0.5 \varphi)}+1\right] \times f(z)+\frac{d-c}{c} \varepsilon_{c} \\
& \times\left[1-\left(\frac{\varepsilon_{c}(1+0.5 \varphi)}{\varepsilon_{c}} \times \frac{c}{d}\left[\left(\frac{d}{c}-1\right)\right.\right.\right. \\
& \left.\left.\left.\times \frac{\varepsilon_{c}}{\varepsilon_{c}(1+0.5 \varphi)}+1\right]\right)\right], \\
f^{\prime}(z)= & (1+0.5 \varphi) \times \frac{c}{d}\left[\left(\frac{d}{c}-1\right) \times \frac{1}{(1+0.5 \varphi)}+1\right] \\
& \times f(z)+\frac{d-c}{c} \varepsilon_{c} \times[1-(1+0.5 \varphi) \\
& \left.\left.\times \frac{c}{d}\left[\left(\frac{d}{c}-1\right) \times \frac{1}{(1+0.5 \varphi)}+1\right]\right)\right] .
\end{aligned}
$$


When concrete stress range, $\sigma_{c} / f_{c}^{\prime}$, is greater than $0.5 f_{c}^{\prime}$, nonlinear creep can occur. In nonlinear creep, creep is not proportional to the stress linearly. For this range of stress, the "affinity hypothesis" can be used to extend Eq. (32) to the nonlinear creep case.

In this theory, affinity coefficient $\eta$ can be defined as follows $[22,23]$ :

$$
\eta=1+2\left(\frac{\sigma_{c}}{f_{c}^{\prime}}\right)^{4}
$$

The creep function in the case of nonlinear creep can be expressed as follows:

For $0.5<\frac{\sigma_{c}}{f_{c}^{\prime}}<0.7$ :

$$
\begin{aligned}
f^{\prime}(z)= & \left.1+\left(0.5+\left(\frac{\sigma_{c}}{f_{c}^{\prime}}\right)^{4}\right) \varphi\right) \\
& \times \frac{c}{d}\left[\left(\frac{d}{c}-1\right) \times \frac{1}{\left(1+\left(0.5+\left(\frac{\sigma_{c}}{f_{c}^{\prime}}\right)^{4}\right) \varphi\right)}+1\right] \\
& \times f(z)+\frac{d-c}{c} \varepsilon_{c} \times[1-((1+(0.5 \\
& \left.\left.+\left(\frac{\sigma_{c}}{f_{c}^{\prime}}\right)^{4}\right) \varphi\right) \times \frac{c}{d}\left[\left(\frac{d}{c}-1\right)\right. \\
& \left.\left.\left.\times \frac{1}{\left(1+\left(0.5+\left(\frac{\sigma_{c}}{f_{c}^{\prime}}\right)^{4}\right) \varphi\right)}+1\right]\right)\right]
\end{aligned}
$$

\section{High-order shear deformable concrete beam}

In the case of shear deformable beam theory, low-order beams theory, such as Timoshenko and Euler-Bernoulli elements, is modified in order to consider warping in cross-section. For an RC shear deformable beam, strain in $x$ direction can be proposed as follows:

$$
\varepsilon(z)=a z^{3}+b z^{2}+e z+f .
$$

It is worth mentioning that, unlike the Reddy beam theory, neutral axis is not located on mid height of the section. This is due to the fact that, in fully cracked concrete section, a time-varying position of the neutral axis may occur. This is the main reason for considering a two-order equation for strain-displacement relation in Reddy beam theory. From a theoretical point of view, solving a third-order equation (see Eq. (35)) is more difficult rather than solving a two-order one.

For calculating parameters $a, b, c$, and $f$, some equations and boundary conditions must be met.

First, it is clear that the second derivative of strain in $z=c-\frac{h}{2}$ is equal to zero. It means that:

$$
\varepsilon^{\prime \prime}{ }_{x x}\left(z=c-\frac{h}{2}\right)=0 .
$$

Second, in $z=c-\frac{h}{2}$, strain in section is zero. This can be given by:

$$
\varepsilon_{x x}\left(z=c-\frac{h}{2}\right)=0 .
$$

According to Figure 3, the third boundary condition can be defined as follows:

$$
\varepsilon_{x x}\left(z=-\frac{h}{2}\right)=\varepsilon_{c} .
$$

The first and second derivatives of the strain equation are thus obtained as follows:

$$
\begin{aligned}
& \varepsilon_{x x}^{\prime}=3 a z^{2}+2 b z+e \\
& \varepsilon_{x x}^{\prime \prime}=6 a z+2 b \\
& \varepsilon_{x x}^{\prime \prime}\left(z=c-\frac{h}{2}\right)=6 a\left(c-\frac{h}{2}\right)+2 b=0 \\
& b=-3 a\left(c-\frac{h}{2}\right) \\
& \varepsilon_{x x}\left(z=c-\frac{h}{2}\right)=a z^{3}+b z^{2}+e z+f=0 \\
& \varepsilon_{x x}\left(z=c-\frac{h}{2}\right)=a\left(c-\frac{h}{2}\right)^{3}+b\left(c-\frac{h}{2}\right)^{2} \\
& \quad+e\left(c-\frac{h}{2}\right)+f=0, \\
& \quad\left(z \varepsilon_{c}-a \frac{h^{3}}{8}-b \frac{h^{2}}{4}-e \frac{h}{2}+f=\varepsilon_{c} .\right. \\
& \quad\left(z=-\frac{h}{2}\right)=a\left(-\frac{h}{2}\right)^{3}+b\left(-\frac{h}{2}\right)^{2}+e\left(-\frac{h}{2}\right)+f \\
& \varepsilon_{x x}\left(z-\frac{h}{2}\right)=a\left(c^{3}-3 c^{2} \frac{h}{2}+3 c \frac{h^{2}}{4}-\frac{h^{3}}{8}\right) \\
& \quad\left(z=\frac{h}{2}\right)+e\left(c-\frac{h}{2}\right)+f=0
\end{aligned}
$$

In addition, $a, b, e, f$, and $\varepsilon_{c}$ are evaluated by Eqs. (41)(43) along with two equilibrium equations related to axial force and bending moment in the concrete section. lows:

Equilibrium equations can be represented as fol-

$$
\begin{aligned}
& \sum F_{x}=0, \\
& w \int_{-\frac{h}{2}}^{-\frac{h}{2}+c} \sigma_{c} d z+A_{s} f_{y}=0,
\end{aligned}
$$




$$
\begin{aligned}
& \sum M_{x x}=0, \\
& w \int_{-\frac{h}{2}}^{-\frac{h}{2}+c} \sigma_{c}\left(z+\frac{h}{2}-c\right) d z=A_{s} f_{y}(d-c) .
\end{aligned}
$$

According to the concrete model proposed by Anis et al. [24], the following equation can be obtained:

$$
\frac{f}{f_{0}}=2.1\left(\frac{\varepsilon}{\varepsilon_{0}}\right)-1.33\left(\frac{\varepsilon}{\varepsilon_{0}}\right)^{2}+0.2\left(\frac{\varepsilon}{\varepsilon_{0}}\right)^{3},
$$

where $f$ is the compression stress in concrete, and $f_{0}$ is the maximum stress at $\varepsilon=\varepsilon_{0}$.

For axial force:

$$
\begin{aligned}
& w \int_{-\frac{h}{2}}^{-\frac{h}{2}+c}\left(2.1\left(\frac{\varepsilon}{\varepsilon_{0}}\right)-1.33\left(\frac{\varepsilon}{\varepsilon_{0}}\right)^{2}+0.2\left(\frac{\varepsilon}{\varepsilon_{0}}\right)^{3}\right) f_{c}^{\prime} d z \\
& +A_{s} f_{y}=0 \\
& \varepsilon_{0}=\frac{2 f_{c}^{\prime}}{E_{c}} \\
& w\left[\int _ { - \frac { h } { 2 } } ^ { - \frac { h } { 2 } + c } \left[\left(1.05 E_{c}\left(a z^{3}+b z^{2}+e z+f\right)\right.\right.\right. \\
& \quad-0.3325 E_{c}^{2} \frac{\left(a z^{3}+b z^{2}+e z+f\right)^{2}}{f_{c}^{\prime}} \\
& \left.\left.\quad+0.025 E_{c}^{3} \frac{\left(a z^{3}+b z^{2}+e z+f\right)^{3}}{f_{c}^{\prime 2}}\right] d z+A_{s} f_{y}\right]=0 .(49)
\end{aligned}
$$

The equilibrium of bending moment in the concrete section is given by:

$$
\begin{aligned}
& w\left[\int _ { - \frac { h } { 2 } } ^ { - \frac { h } { 2 } + c } \left[\left(1.05 E_{c}\left(a z^{3}+b z^{2}+e z+f\right)\right.\right.\right. \\
& -0.3325 E_{c}^{2} \frac{\left(a z^{3}+b z^{2}+e z+f\right)^{2}}{f_{c}^{\prime}} \\
& \left.+0.025 E_{c}^{3} \frac{\left(a z^{3}+b z^{2}+e z+f\right)^{3}}{f_{c}^{\prime 2}}\right]\left(z+\frac{h}{2}-c\right) d z \\
& \left.+A_{s} f_{y}(d-c)\right]=0 .
\end{aligned}
$$

Solving five parameters $a, b, e, f$, and $\varepsilon_{c}$ in Eq. (51) leads to obtaining strain distribution along crosssection height as follows:

$$
\begin{gathered}
b=-3 a\left(c-\frac{h}{2}\right), \\
a\left(c^{3}-3 c^{2} \frac{h}{2}+3 c \frac{h^{2}}{4}-\frac{h^{3}}{8}\right)+b\left(c^{2}-2 c \frac{h}{2}+\frac{h^{2}}{4}\right) \\
+e\left(c-\frac{h}{2}\right)+f=0, \\
-a \frac{h^{3}}{8}-b \frac{h^{2}}{4}-e \frac{h}{2}+f=\varepsilon_{c}, \\
w\left[\int _ { - \frac { h } { 2 } } ^ { - \frac { h } { 2 } + c } \left[1.05 E_{c}\left(a z^{3}+b z^{2}+e z+f\right)\right.\right. \\
+0.3325 E_{c}^{2} \frac{\left(a z^{3}+b z^{2}+e z+f\right)^{2}}{f_{c}^{\prime}} \\
+\int_{-\frac{h}{2}}^{-\frac{h}{2}+c}\left[1.05 E_{c}\left(a z^{3}+b z^{2}+e z+f\right)\right. \\
\left.\left.+0.025 E_{c}^{3} \frac{\left(a z^{3}+b z^{2}+e z+f\right)^{3}}{f_{c}^{\prime 2}}\right] d z+A_{s} f_{y}\right]=0, \\
\left.f_{c}^{\prime 2} f_{y}(d-c)\right]=0.3325 E_{c}^{2} \frac{\left(a z^{3}+b z^{2}+e z+f\right)^{2}}{f_{c}^{\prime}}
\end{gathered}
$$

Detailed integration of Eqs. (49) and (50) may be found in Appendix A.

Figure 4 shows a summary of the proposed method.

\section{Creep formulation}

To develop the proposed theory for shear-deformable beam, the effect of creep on strain distribution is considered (see Figure 5). It is assumed that the strain in sections for creep effect is considered by linear transformation.

$$
\varepsilon_{1}(z)=a^{\prime} z^{3}+b^{\prime} z^{2}+e^{\prime} z+f^{\prime} .
$$

By integrating the cross-section areas, the equilibrium force and moment are given as follows: 


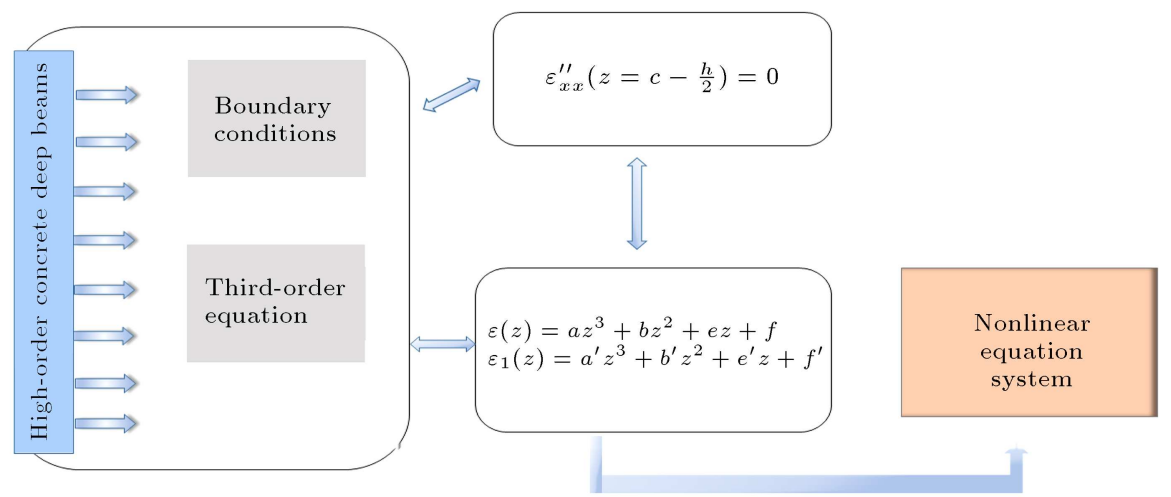

Figure 4. A summary of the proposed method.
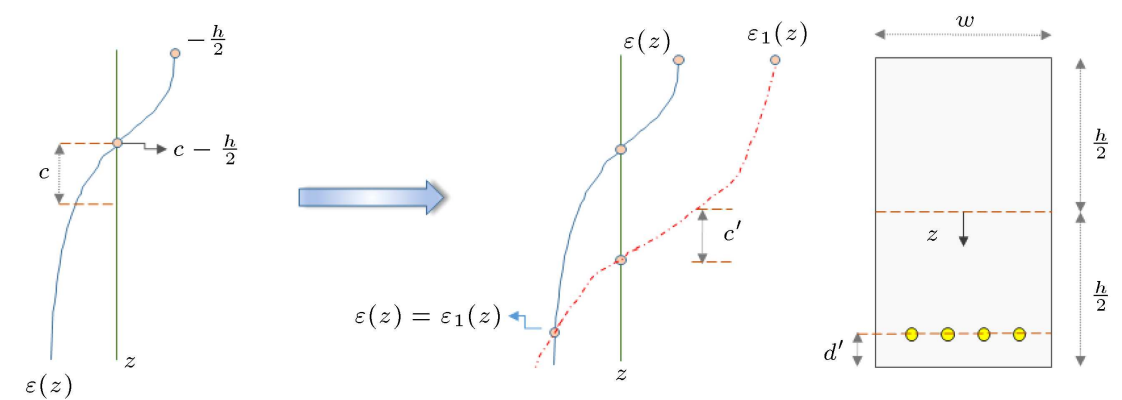

Strain (without time effect)

Strain (with time effect)

Figure 5. Strain distribution in shear-deformable RC beam.

$$
\begin{aligned}
& w \int_{-\frac{h}{2}}^{c^{\prime}}\left(2.1\left(\frac{\varepsilon}{\varepsilon_{0}}\right)-1.33\left(\frac{\varepsilon}{\varepsilon_{0}}\right)^{2}+0.2\left(\frac{\varepsilon}{\varepsilon_{0}}\right)^{3}\right) f_{c}^{\prime} d z \\
& \quad+A_{s} f_{y}=0
\end{aligned}
$$$$
w\left[\int _ { - \frac { h } { 2 } } ^ { c ^ { \prime } } \left[\left(1.05 E_{c}\left(a^{\prime} z^{3}+b^{\prime} z^{2}+e^{\prime} z+f^{\prime}\right)\right.\right.\right.
$$$$
-0.3325 E_{c}^{2} \frac{\left(a^{\prime} z^{3}+b^{\prime} z^{2}+e^{\prime} z+f^{\prime}\right)^{2}}{f_{c}^{\prime}}
$$$$
\left.\left.+0.025 E_{c}^{3} \frac{\left(a^{\prime} z^{3}+b^{\prime} z^{2}+e^{\prime} z+f^{\prime}\right)^{3}}{f_{c}^{\prime 2}}\right] d z+A_{s} f_{y}\right]
$$$$
=0 \text {, }
$$

$$
\begin{array}{r}
w\left[\int _ { - \frac { h } { 2 } } ^ { c ^ { \prime } } \left[\left(1.05 E_{c}\left(a^{\prime} z^{3}+b^{\prime} z^{2}+e^{\prime} z+f^{\prime}\right)\right.\right.\right. \\
-0.3325 E_{c}^{2} \frac{\left(a^{\prime} z^{3}+b^{\prime} z^{2}+e^{\prime} z+f^{\prime}\right)^{2}}{f_{c}^{\prime}}
\end{array}
$$

$$
\begin{aligned}
& \left.+0.025 E_{c}^{3} \frac{\left(a^{\prime} z^{3}+b^{\prime} z^{2}+e^{\prime} z+f^{\prime}\right)^{3}}{f_{c}^{\prime 2}}\right] \\
& \left.\left(z+\frac{h}{2}-c\right) d z+A_{s} f_{y}\left(d-c^{\prime}\right)\right]=0 .
\end{aligned}
$$

Appropriate boundary conditions are as follows:

$$
\begin{aligned}
& \varepsilon_{1}\left(z=-\frac{h}{2}\right)=\varepsilon\left(z=-\frac{h}{2}\right)(1+0.5 \varphi) \\
& \varepsilon_{1}\left(z=\frac{h}{2}-d^{\prime}\right)=\varepsilon\left(z=\frac{h}{2}-d^{\prime}\right), \\
& \varepsilon_{1}^{\prime \prime}\left(z=c^{\prime}\right)=0, \\
& w\left[\int _ { - \frac { h } { 2 } } ^ { c ^ { \prime } } \left[1.05 E_{c}\left(a^{\prime} z^{3}+b^{\prime} z^{2}+e^{\prime} z+f^{\prime}\right)\right.\right. \\
& \quad-0.3325 E_{c}^{2} \frac{\left(a^{\prime} z^{3}+b^{\prime} z^{2}+e^{\prime} z+f^{\prime}\right)^{2}}{f_{c}^{\prime}} \\
& \left.+0.025 E_{c}^{3} \frac{\left.\left.\left(a^{\prime} z^{3}+b^{\prime} z^{2}+e^{\prime} z+f^{\prime}\right)^{3}\right] d z+A_{s} f_{y}\right]=0,}{f_{c}^{\prime 2}}\right]
\end{aligned}
$$




$$
\begin{aligned}
& w\left[\int _ { - \frac { h } { 2 } } ^ { c ^ { \prime } } \left[1.05 E_{c}\left(a^{\prime} z^{3}+b^{\prime} z^{2}+e^{\prime} z+f^{\prime}\right)\right.\right. \\
& \quad-0.3325 E_{c}^{2} \frac{\left(a^{\prime} z^{3}+b^{\prime} z^{2}+e^{\prime} z+f^{\prime}\right)^{2}}{f_{c}^{\prime}} \\
& \left.+0.025 E_{c}^{3} \frac{\left(a^{\prime} z^{3}+b^{\prime} z^{2}+e^{\prime} z+f^{\prime}\right)^{3}}{f_{c}^{\prime 2}}\right] \\
& \left.\left(z+\frac{h}{2}-c\right) d z+A_{s} f_{y}\left(d-c^{\prime}\right)\right]=0
\end{aligned}
$$

The coupled system of Eq. (56) is more complicated than the equations of Euler-Bernoulli beam theory and must be solved by an analytical method.

In addition, in an elastic range, the radius of curvature of the RC beam at its neutral axis can be given by:

$$
\frac{1}{\rho}=\frac{M}{E I},
$$

where $M$ is the bending moment, $E$ is the modulus of elasticity, and $I$ is the second moment of inertia. The curvature component resulting from creep can be defined by the following equation:

$$
\kappa_{\text {creep }}\left(t, t_{0}\right)=\frac{M_{\text {creep }}}{E_{c}\left(t_{0}\right) I_{\text {creep }}},
$$

where $I_{\text {creep }}$ is the modified moment of inertia due to a gradual change in the position of neutral axis under creep of concrete effect.

Finally, total curvature due to short- and longterm loading at any cross-section can be written as follows:

$$
\kappa_{\text {total }}\left(t, t_{0}\right)=\kappa_{\text {creep }}+\kappa_{0} .
$$

For instance, by applying the assumption of parabolic distribution of strain and curvature along the RC beam, mid-span deflection of a simply supported beam can be given by Gilbert and Ranzi [19]:

$$
\delta_{c}=\frac{l^{2}}{96}\left(\kappa_{A}+10 \kappa_{C}+\kappa_{B}\right),
$$

where $\kappa_{A}$ and $\kappa_{B}$ are the curvatures at supports $A$ and $B$, respectively. The curvature of mid-span of simplysupported beam is defined by $\kappa_{C}$.

\section{Numerical examples}

The validity of the proposed model is exhibited by some numerical examples. To validate the proposed model, some numerical examples reported in literature are used. The effect of creep on deflection of $\mathrm{RC}$ beams is analyzed by FEM, AEMM, CEB-FIP model, Euro code, and experimental studies. First, three shallow concrete beams tested by Gilbert [25] are analyzed. Second, the results of experimental works by Reybrouck et al. [26] respecting simply-supported $\mathrm{RC}$ beams with different reinforcements are used to verify the proposed method. Finally, an RC deep beam is modeled and compared by FEM and AEMM approaches. Most test results in literatures are focused on shallow RC beams, and deep RC beams have received insignificant attention in the literature. In this example, the effect of nonlinearity in strain distribution is taken into account to identify the effect of shear in the concrete sections.

\subsection{Simply supported beams (test by Gilbert [25])}

In this section, the effect of linear creep on deflection of ordinary RC beams is investigated. Nonlinear creep effects due to high loading level will be discussed in Section 5.2.

ABAQUS suggests several models to simulate nonlinear behavior of concrete. Concrete Damaged Plasticity (CDP) model of concrete is different from others, because it is able to separately simulate compressive and tensile behavior of concrete and introduce the reduction of elastic modulus. In addition to static loads, the model is also capable of modeling cyclic loads. It should be noted that the behavioral model uses Dracker-Prager failure criteria with Lubliner's yield function [27]. To calculate the long-term deflection of concrete beams due to creep and shrinkage, subroutines UMAT and UEXPAN are used. It is worth noting that ACI 209-08 is used to complete UMAT subroutine in ABAQUS for calculating creep coefficient. A complete flowchart for the implementation of creep and shrinkage in ABAQUS is shown in Figure 6.

The software was initially examined based on the experimental results of the long-term deflection of shallow concrete beams by Gilbert [25]. According to the validation of finite element models of $\mathrm{RC}$ beams, it can be concluded that the software is able to properly model concrete beams including effects of creep and shrinkage. In Gilbert's test, 6 conventional concrete beams with different geometries and loading conditions were placed under long-term loading. All specimens were simply supported beams with a span of $3.5 \mathrm{~m}$ under constant load for 400 days. Applied force varied from $11.8 \mathrm{kN}$ to $27 \mathrm{kN}$. Geometrical characteristics of tested beams are given in Table 2 and Figure 7 .

The analytical results obtained from the implementation of subroutine UMAT and UEXPAN are compared with the test results. A step-by-step analysis based on Kelvin chain theory is implemented by ABAQUS. In fact, the stress-strain relation for concrete as a viscoelastic material can be modeled by 


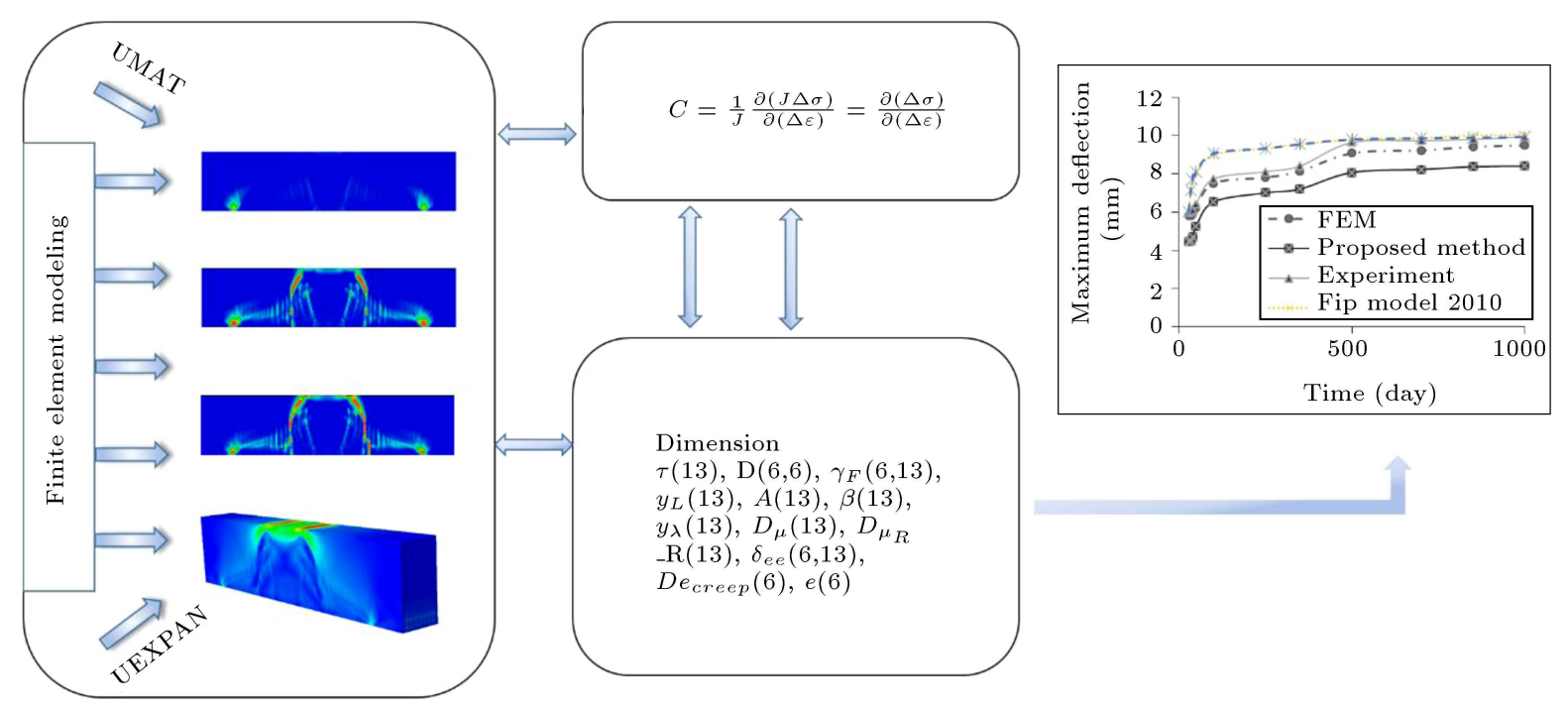

Figure 6. The outline of creep and shrinkage analysis coded in ABAQUS using UMAT and UEXPAN.

Table 2. Geometrical properties of RC shallow beams [25].

\begin{tabular}{ccccccc}
\hline Beam & Rebar no. & Rebar Dia. $(\mathbf{m m})$ & $\boldsymbol{A}_{\boldsymbol{s}}\left(\mathbf{m m}^{\mathbf{2}}\right)$ & $\boldsymbol{C}_{\boldsymbol{b}} \mathbf{( \mathbf { m m } )}$ & $\boldsymbol{C}_{\boldsymbol{s}}(\mathbf{m m})$ & $\boldsymbol{S}(\mathbf{m m})$ \\
\hline B1-a & 2 & 16 & 400 & 40 & 40 & 150 \\
B1-b & 2 & 16 & 400 & 40 & 40 & 150 \\
B2-a & 2 & 16 & 400 & 25 & 25 & 180 \\
B2-b & 2 & 16 & 400 & 25 & 25 & 180 \\
B3-a & 3 & 16 & 600 & 25 & 25 & 90 \\
B3-b & 3 & 16 & 600 & 25 & 25 & 90 \\
\hline
\end{tabular}

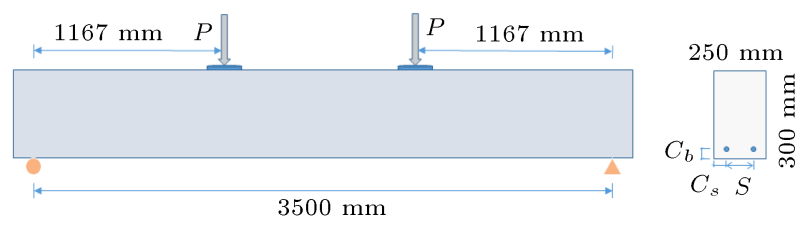

Figure 7. Geometry of the RC beams.

a rheological model such as Kelvin chain theory. The parameters of Kelvin chain model can be determined from the continuous spectrum concept as an agedependent material. To ensure algorithm stability, an unconditional method called exponential algorithm is used to overcome numerical instability [28]. An outline of the creep and shrinkage analysis based on a ratetype creep model is shown in Figure 8. Creep under constant environmental factors and stress is expressed by a compliance function $J\left(t, t^{\prime}\right)$ defined as strain $\varepsilon$ at time $t$ caused by a unit uniaxial stress applied at time $t^{\prime}$. As previously mentioned, the relationship between stress and strain in concrete can be expressed by Kelvin chain model. The model includes a number of Kelvin units called $\mu$. Each Kelvin unit includes a spring with hardness of $E_{\mu}(t)$ and a damper with viscosity of $\eta_{\mu}(t)=E_{\mu}(t) \tau_{\mu}$, which are in parallel. In fact, parameter $\tau_{\mu}$ is known as retardation time. In the systematic analysis, values of $E_{\mu}(t)$ and $\eta_{\mu}(t)$ can be assumed constant at each time interval, and their proportional amounts will be adopted in the next step.

Figure 9 displays time variation of the maximum deflection based on the experimental and analytical analyses.

As seen in Figure 9, the proposed finite element analytical model shows good accuracy concerning changes in reinforcement and loading on beams. The model does not demonstrate a notable deviation according to changes of parameters, and it properly matches with experimental results. Since the creep model of ACI does not consider drying creep, analytical results are subject to $1 \%$ to $6 \%$ deviation from laboratory results after 400 days of loading. In the case of the proposed model, shrinkage is not considered in the mathematical formulation, and curvature as its formulation demonstrates intrinsic errors. By considering the significant effect of shrinkage, the curvature on the maximum deflection of RC beams B1-a, B2-b, and B3-b is estimated to be subject to $18 \%, 23 \%$, and $27 \%$ deviations from experimental results, respectively. 


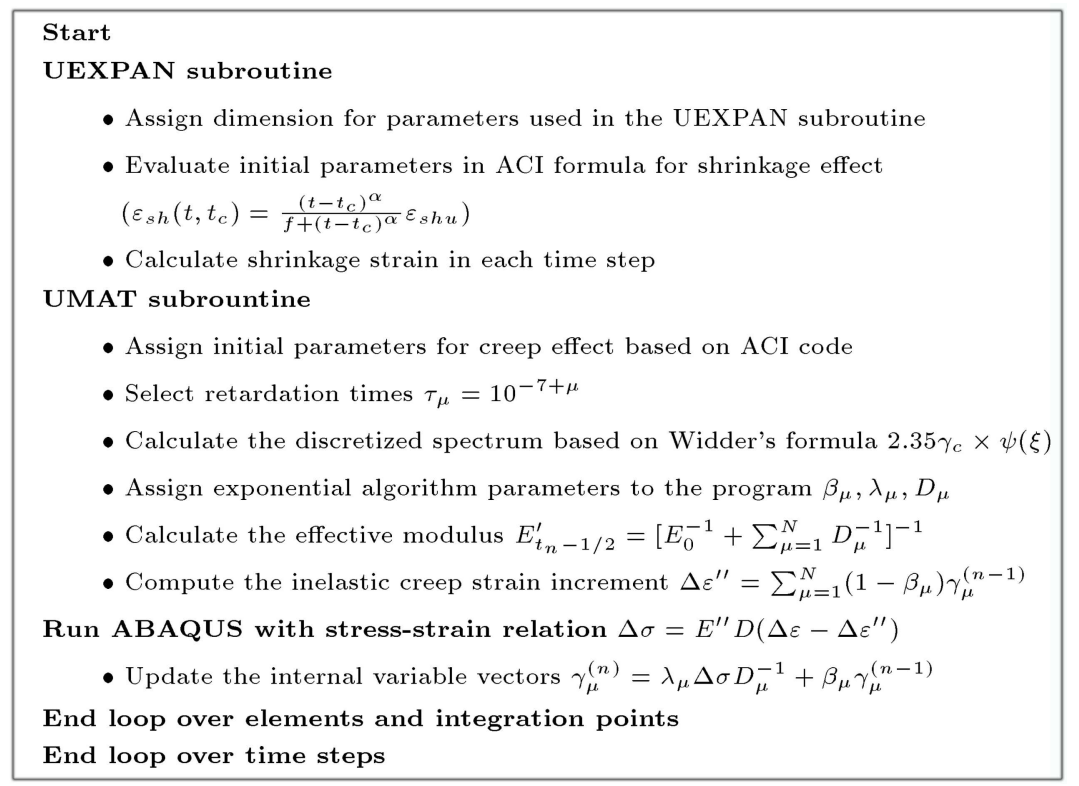

Figure 8. Outline of the creep and shrinkage analysis coded in UMAT and UEXPAN [28].

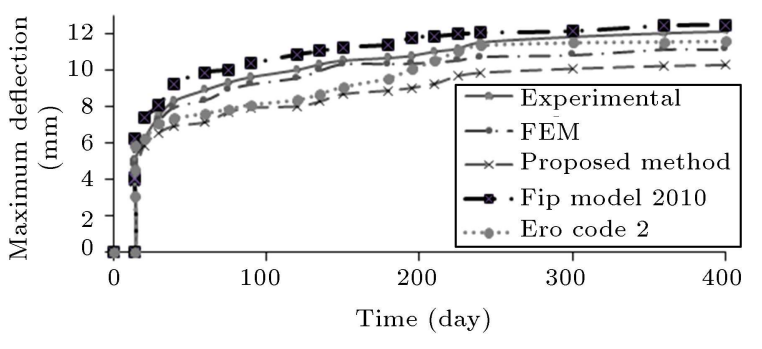

(a)

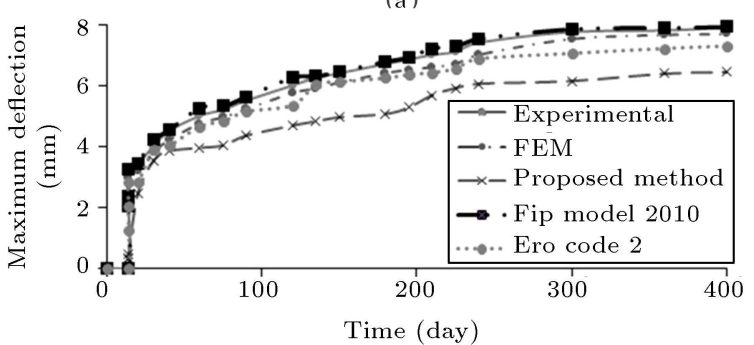

(b)

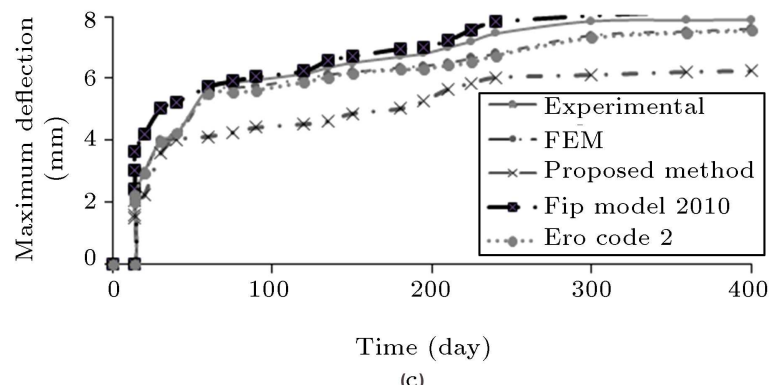

Figure 9. Results obtained from different models and experiments: (a) B1-a, (b) B2-b, and (c) B3-b.

However, the proposed method can capture the effect of creep on RC beam by considering shrinkage and the modifications to the curvature along length of beams.

\subsection{Simply-supported beams (test by Reybrouck et al. [26])}

To study the effect of creep on long-term deflection of $\mathrm{RC}$ beams and complete the verification of the proposed method, simply supported reinforced concrete beams tested by Belgian research campaign [26] were investigated as a second example.

In Reybrouck's study [26], some simply supported beams were loaded at different loading levels. Geometry details of cross-section and material properties are shown in Table 3 and Figures 10 and 11.

The maximum long-term deflection of the simply supported RC beam is compared in Figure 12. Three different methods are shown in order to verify the proposed method.

In this Figure, the solid line corresponds to the proposed method, as described earlier. It can be observed that the maximum difference between the proposed method and experimental results in 10000 days is about 18\%. The difference between these methods justifies the effect of shrinkage, which is not considered in the proposed method. It is worth mentioning that, in this example, a shallow beam is

Table 3. Material properties of concrete.

\begin{tabular}{lc}
\hline Input parameters & $\begin{array}{c}\text { Parameters } \\
\text { range }\end{array}$ \\
\hline Concrete strength, $f_{c}^{\prime}(\mathrm{MPa})$ & $35-50$ \\
Concrete elasticity modulus, $E_{c}(\mathrm{MPa})$ & $27,800-35,500$ \\
Steel elasticity modulus, $E_{s}(\mathrm{MPa})$ & 195,500 \\
Creep coefficient, $\varphi$ & $0.5-4$ \\
Aging coefficient, $\chi$ & $0.7-0.9$ \\
\hline
\end{tabular}




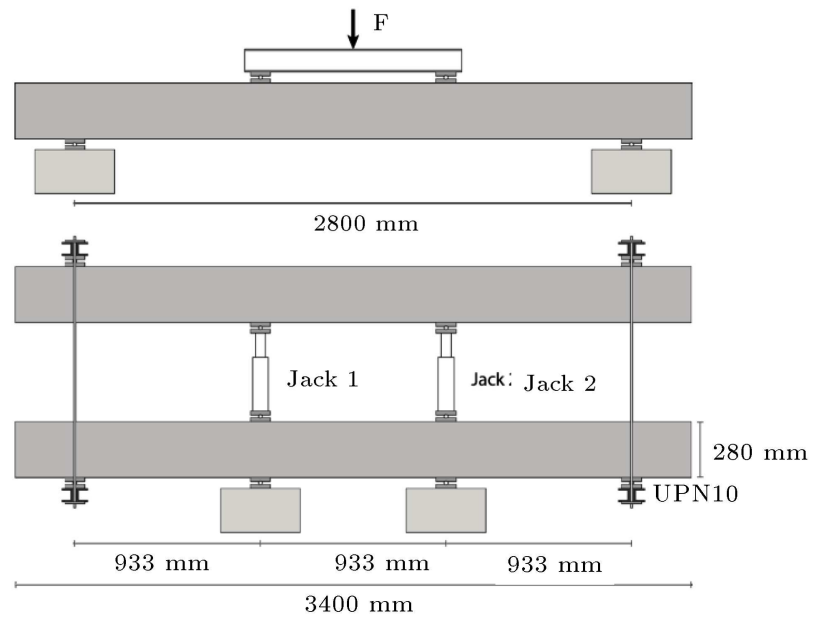

Figure 10. Geometry of simply supported beams [26].

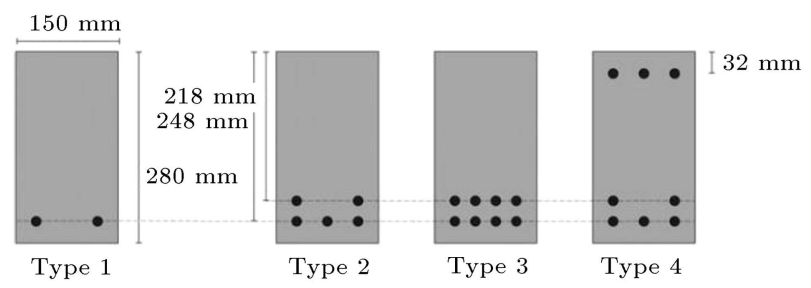

Figure 11. Geometry of simply supported beams [26].

examined and Euler-Bernoulli assumption is found to be the most practicable. Despite good accuracy of fib model code 2010 and Euro code 2 in the case of shallow $\mathrm{RC}$ beam without shear reinforcement as shown in Figure 12, it appears that, in the case of deep RC beams with stirrup, a more accurate approach such as finite element method is essential to predict a more realistic response of $\mathrm{RC}$ beams.

\subsection{Simply supported RC deep beam}

To investigate the effect of creep of concrete on shearsensitive members, a simply supported deep beam is modeled. According to the ACI Committee 318 [29], deep beams are defined as members with a span-todepth ratio smaller than $4(L / h<4)$ and a shear span-to-depth ratio smaller than $2(a / d<2)$. Based on experimental and analytical studies, the assumption of strain linearity over cross-section depth is found to be not valid. The proposed method overcomes this shortcoming by a third-order strain distribution in concrete section. Figure 13 and Table 4 show material properties and geometry conditions of the $\mathrm{RC}$ deep beam.

As is shown in Figure 14, creep and shrinkage analysis using fib model 2010 and Euro code 2 underestimate the deflection of $\mathrm{RC}$ deep beams. It appears that shear behavior plays a dominant role in timedependent deflection of RC deep beam. For beam with $\frac{a}{b}=0.5$, maximum deflection of RC deep beam using FEM and the proposed method is about $20 \%$ greater
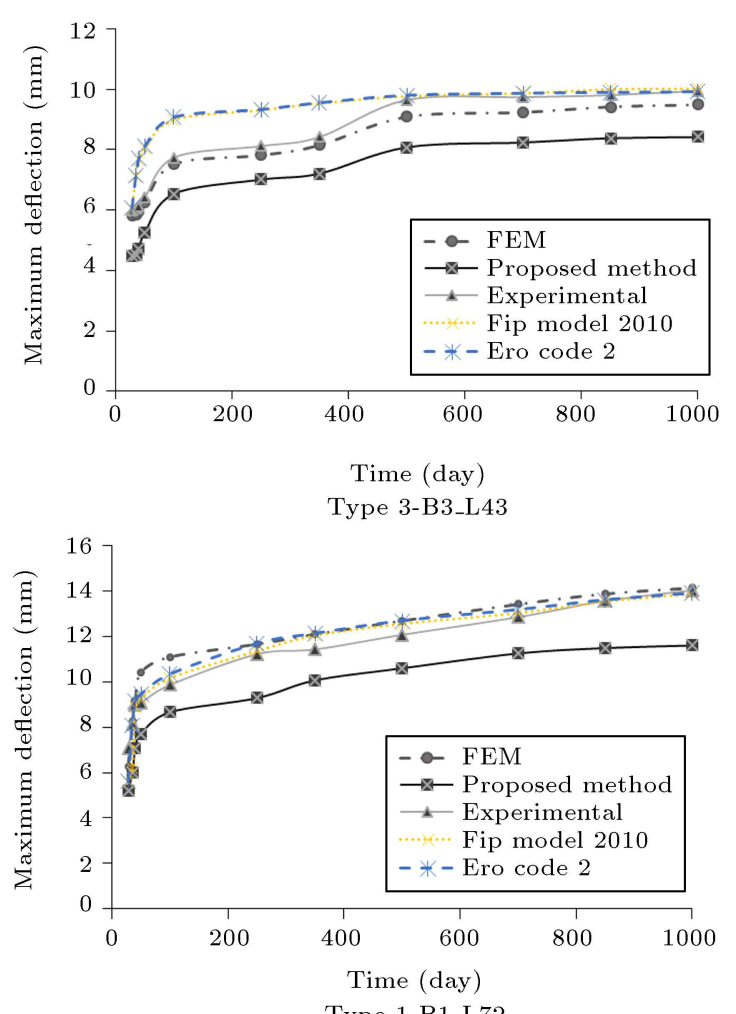

Type 1-B1_L72

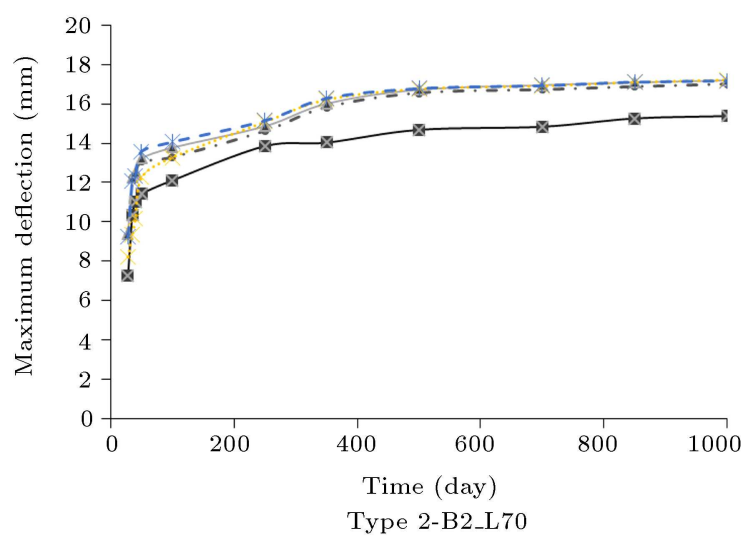

Figure 12. Maximum long-term deflection of simply supported beam.

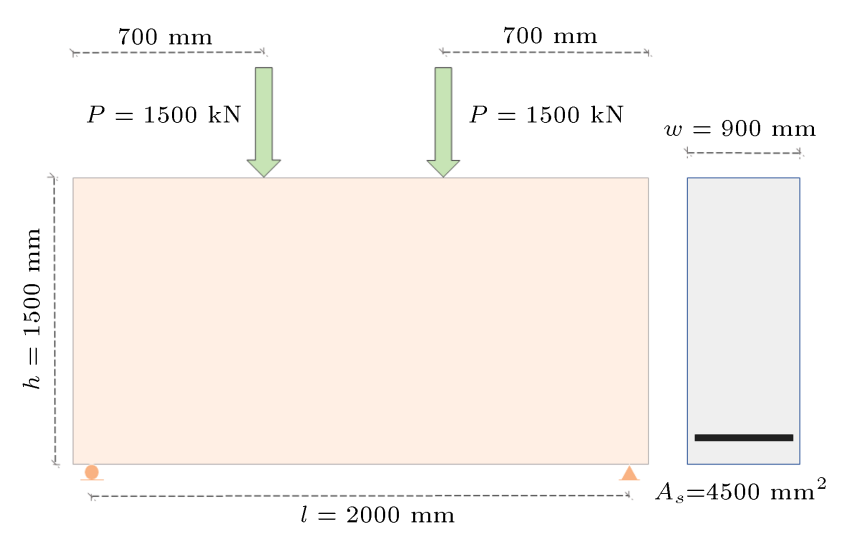

Figure 13. Geometry and loading of a simply supported $\mathrm{RC}$ deep beam. 
Table 4. Material properties of concrete.

\begin{tabular}{lc}
\hline Input parameters & $\begin{array}{c}\text { Parameters } \\
\text { range }\end{array}$ \\
\hline Concrete strength, $f_{c}^{\prime}(\mathrm{MPa})$ & 28 \\
Concrete elasticity modulus, $E_{c}(\mathrm{MPa})$ & 25,000 \\
Steel elasticity modulus, $E_{s}(\mathrm{MPa})$ & 200,000 \\
Creep coefficient, $\varphi$ & $0.5-4$ \\
Aging coefficient, $\chi$ & 0.65 \\
\hline
\end{tabular}

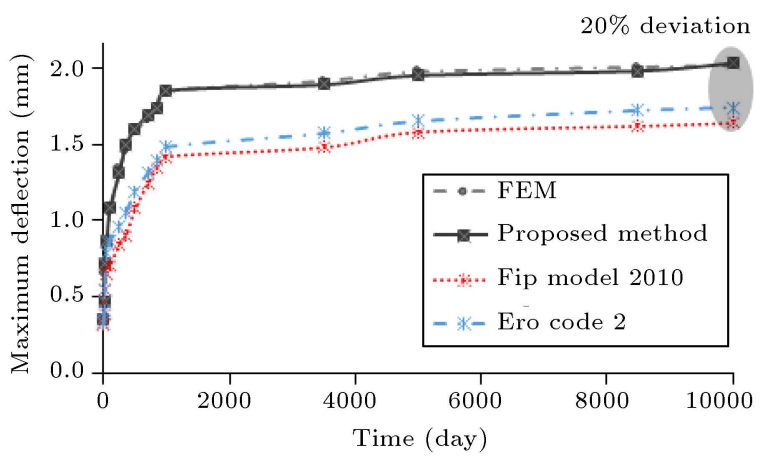

Figure 14. Maximum long-term deflection of RC deep beam.

than the deflection calculated using codes for linear creep range. In fib model and Euro code, the effect of strain nonlinearity of strain in the concrete section is not taken into account. Unlike deep concrete beams, as indicated in Figure 12, fib model, FEM, and Euro code can perfectly fit the experimental data in the case of shallow RC beams. However, in the case of deep RC beams, the effectiveness of fib model and Euro code requires further experimental observation and more accurate theoretical analysis. Unlike fib model and Euro code, in the proposed method, nonlinearity of strain has been considered in the third-order equation in order to predict the deflection of shear sensitive concrete beams accurately.

\section{Conclusions}

A new method based on strain distribution in concrete section for creep effect was presented. First, a new formulation of linear and nonlinear creeps in shallow RC beam derived from the linear strain distribution theory was presented. Then, a new theory was proposed to characterize the effect of creep on shear deformable $\mathrm{RC}$ beams. In the formulation presented in this work, it is assumed that a third-order equation governs the nonlinear strain distribution over cross-section depth. Furthermore, the proposed method was compared with fib model 2010 model, Euro code, and finite element method by using three numerical examples.

In simply supported RC beams tested by Gilbert, the maximum difference between the experimental results and the results of the proposed method was about $27 \%$. Unlike the previous experiment, in the proposed method, shrinkage was not taken into account and, thus, the proposed method and experiments were in reasonably good agreement. In simply supported RC beams tested by Reybrouck et al. [26], the proposed method was examined in the case of nonlinear creep due to high stress level. In addition, experimental results were compared with fib and Euro code models; subsequently, the proposed method was compared with fib model code 2010 and Euro codes. Results showed that the proposed model might be found useful to investigate the effect of high sustained loading level in shallow RC beams. Finally, the effectiveness of the proposed method in the case of deep $\mathrm{RC}$ beams was investigated. It is well known that, in commercial design codes, the effect of strain nonlinearity in section was not considered and limited to linear strain theory. Thus, the proposed method could potentially yield significant benefit for predicting long-term deflection in deep RC beams. Results presented in Section 5.3 showed that the proposed method provided a powerful and robust tool for estimating the long-term deflection of sensitive shear elements. Effect of shear strain in sections leads to an increase in creep strain, compared to the linear strain theory. Based on the knowledge scope of this study, a modification factor of 1.2 may be appropriate in design codes owing to the creep effect considered in the final deflection of shear sensitive concrete beams. However, this shear coefficient should be further examined using complete experimental works to cast new light on deep RC beams' behavior at high and moderate levels of loading.

\section{References}

1. Wang, C.M., Reddy, J.N., and Lee K.H., Shear Deformable Beams and Plates-Relationships with Classical Solutions, UK, Elsevier (2000).

2. Levinson, M.A. "New rectangular beam theory", Journal of Sound and Vibration, 74(1), pp. 81-87 (1981).

3. Heyliger, P.R. and Reddy, J.N. "A higher order beam finite element for bending and vibration problems", Journal of Sound and Vibration, 126(2), pp. 309-326 (1988).

4. Challamel, N. "High-order shear beam theories and enriched continuum", Mechanics Research Communications, 38(5), pp. 388-392 (2011).

5. Sayyad, A.S. "Comparison of various refined beam theories for the bending and free vibration analysis of thick beams", Applied and Computational Mechanics, 5(2), pp. 217-230 (2011).

6. Sayyad, A.S. and Ghugal, Y.M. "A unified shear deformation theory for the bending of isotropic, functionally graded, laminated and sandwich beams and plates", International Journal of Applied Mechanics, 9(1), pp. 1-36 (2017). 
7. Dongil, S., Soomin, C., Jang G.W., and Kim Y.Y. "High-order beam theory for static and vibration analysis of composite thin-walled box beam", Composite Structures, 206, pp. 140-154 (2018).

8. Le, C.A. and Kosmatka, J.B. "On the analysis of prismatic beams using first-order warping functions", International Journal of Solid and Structures, 29(7), pp. 879-891 (1992).

9. Sayyad, A.S. "Comparison of various refined beam theories for the bending and free vibration analysis of thick beams", Applied and Computational Mechanics, 5(2), pp. 217-230 (2011).

10. Polizzotto, C. "From the Euler-Bernoulli beam to the Timoshenko one through a sequence of Reddy-type shear deformable beam models of increasing order", European Journal of Mechanics-A/Solids, 53, pp. 62$74(2015)$.

11. Minera, S., Panti, M., Carrera, E., Petrolo, M., Weaver, P.M., and Pirrera, A. "Three-dimensional stress analysis for beam-like structures using Serendipity Lagrange shape functions", International Journal of Solid and Structures, 141-142, pp. 279-296 (2018).

12. Kim, M.S., Kim, H., Park, H., Ahn, N., and Lee, Y.H. "Evaluation of shear behavior of deep beams with shear reinforced with GFRP plate", Scientia Iranica, 22(6), pp. 2142-2149 (2015).

13. Karaman, S.I. "Shear behavior of reinforced concrete deep beams", PhD Dissertation, Department of civil engineering, University of Sheffield, UK (2016).

14. Fib Model Code for Concrete Structures, Germany, Ernst \& Sohn (2013).

15. Euro-code 2, Design of Concrete Structures - Part 1-1, General Rules and Rules for Building, Brussels. (2004).

16. ACI Committee 209R-08, Guide for Modeling and Calculating Shrinkage and Creep in Hardened Concrete, American Concrete Institute, Farmington Hills, USA (2008).

17. Bazant, Z.P. and Murphy W.P. "Creep and shrinkage prediction model for analysis and design of concrete structures-model B3", Materiaux et Constructions, 28(180), pp. 357-365 (1995).

18. Lakho, N.A. and Zadari, M.A. "Long-term flexural behavior of reinforced baked clay beams", Scientia Iranica, 24(3), pp. 877-883 (2017).

19. Gilbert, R.I. and Ranzi, G., Time-dependent Behavior of Concrete Structures, New York, Spon Press (2011).

20. Gilbert, R.I. "Time-dependent stiffness of cracked reinforced and composite concrete slabs", Procedia Engineering, 57, pp. 19-34 (2013).

21. Bazant, Z.P. "Prediction of concrete creep effects using age-adjusted effective modulus method", Journal Proc., 69(4), pp. 212-219 (1972).

22. Fernandez Ruiz, M., Muttoni, A., and Gambarova, P.G. "Relationship between nonlinear creep and cracking of concrete under uniaxial compression", Journal of Advanced Concrete Technology, 5(3), pp. 383-393 (2007).
23. Tasevski, D., Fernandez Ruiz, M., and Muttoni, A. "Compressive strength and deformation capacity of concrete under sustained loading and low stress rates", Journal of Advanced Concrete Technology, 16, pp. 396415 (2018).

24. Anis, M.A., Farid, B.J., and Al-Janabi, A.I.M. "Stressstrain relationship for concrete in compression mode of local materials", JKAU. Engineering Science, 2, pp. 183-194 (1990).

25. Gilbert, R.I. "Calculation of long-term deflection", CIA Seminar, Brisbane (April 2008).

26. Reybrouck, N., Criel, P., Mullem, T.V., and Caspeele, R. "Long-term data of reinforced concrete beams subjected to high sustained loads and simplified prediction method", Structural Concrete, 18(6), pp. 850-861 (2017).

27. Lubliner, J., Oliver, J., Oller, S., and Onate E. "A plastic-damage model for concrete", International Journal of Solid and Structures, 25(1), pp. 299-329 (1989).

28. Qiang, Y., Bazant, Z.P., and Wendner, R. "Improved algorithm for efficient and realistic creep analysis of large creep-sensitive concrete structures", ACI Structural Journal, 109(5), pp. 665-675 (2012).

29. ACI Committee 318-14, Building Code Requirements for Structural Concrete and Commentary, American Concrete Institute, Farmington Hills, USA (2014).

\section{Appendix A}

Detailed integration of Eqs. (49) and (50) can be expressed as follows:

A1:

$$
\begin{aligned}
& \int_{-\frac{h}{2}}^{-\frac{h}{2}+c}\left[1.05 E_{c}\left(a z^{3}+b z^{2}+e z+f\right)\right. \\
& \quad-0.3325 E_{c}^{2} \frac{\left(a z^{3}+b z^{2}+e z+f\right)^{2}}{f_{c}^{\prime}} \\
& +0.025 E_{c}^{3} \frac{\left(a z^{3}+b z^{2}+e z+f\right)^{3}}{\left.f_{c}^{\prime 2}\right] d z} \\
& \quad=\frac{1}{2 f_{c}^{\prime 2}} E_{c}\left(2 ( c - \frac { h } { 2 } ) \left(0.025 f^{3} E_{c}^{2}\right.\right. \\
& +f^{2} E_{c}\left(-0.3325 f_{c}^{\prime}+0.102+0.019 a\left(c-\frac{h}{2}\right)^{2}\right. \\
& \left.+b(0.025 c-0.0125 h))\left(c-\frac{h}{2}\right) E_{c}\right)^{2} \\
& +f\left(1.05 f_{c}^{\prime 2}+\left(-0.88-0.162 a\left(c-\frac{h}{2}\right)^{2}\right.\right.
\end{aligned}
$$




$$
\begin{aligned}
& +b(-0.22 c+0.108 h))\left(c-\frac{h}{2}\right) f_{c}^{\prime} E_{c} \\
& +\left(0.18+\left(b\left(0.102+0.025 a\left(c-\frac{h}{2}\right)^{2}\right)\right.\right. \\
& +0.015 b^{2}\left(c-\frac{h}{2}\right)+a(0.018+0.011 a \\
& \left.\left.\left.\left.\left(c-\frac{h}{2}\right)^{2}\right)\left(c-\frac{h}{2}\right)\right)\left(c-\frac{h}{2}\right)\right)\left(c-\frac{h}{2}\right)^{2} E_{c}^{2}\right) \\
& +\left(c-\frac{h}{2}\right)\left(\left(1.43+0.26 a\left(c-\frac{h}{2}\right)^{2}\right.\right. \\
& +b(0.35 c-0.175 h)) f_{c}^{\prime 2}+(-0.8 \\
& +\left(b\left(-0.44-0.11 a\left(c-\frac{h}{2}\right)^{2}\right)\right. \\
& -0.065 b^{2}\left(c-\frac{h}{2}\right)+a(-0.35 \\
& \left.\left.\left.-0.046 a\left(c-\frac{h}{2}\right)^{2}\right)\left(c-\frac{h}{2}\right)\right)\left(c-\frac{h}{2}\right)\right) \\
& \left(c-\frac{h}{2}\right) f_{c}^{\prime} E_{c}+(0.12+(b(0.11 \\
& \left.+a\left(0.06+0.008 a\left(c-\frac{h}{2}\right)^{2}\right)\left(c-\frac{h}{2}\right)^{2}\right) \\
& +b^{2}\left(0.034+0.009 a\left(c-\frac{h}{2}\right)^{2}\right)\left(c-\frac{h}{2}\right) \\
& +a\left(0.09+a\left(0.025+0.002 a\left(c-\frac{h}{2}\right)^{2}\right)\right. \\
& \left.\left.\left.\left(c-\frac{h}{2}\right)^{2}\right)\right)\left(c-\frac{h}{2}\right)+0.003 b^{3}\left(c-\frac{h}{2}\right)^{2}\right) \\
& \left.\left(c-\frac{h}{2}\right)\right)\left(c-\frac{h}{2}\right)^{2} E_{c}^{2}+h\left(0.025 f^{3} E_{c}^{2}\right. \\
& +f^{2} E_{c}\left(-0.3325 f_{c}^{\prime}+h(-0.051+0.006 b h\right. \\
& \left.\left.-0.02 a h^{2}\right) E_{c}\right)+f\left(1.05 f_{c}^{\prime 2}+h(0.44\right.
\end{aligned}
$$

$$
\begin{aligned}
& \left.-0.054 b h+0.02 a h^{2}\right) f_{c}^{\prime} E_{c}+h^{2}(0.046 \\
& -0.013 b h+0.005 a h^{2}+0.0009 b^{2} h^{2} \\
& \left.\left.-0.00078 a b h^{3}+0.00017 a^{2} h^{4}\right) E_{c}^{2}\right) \\
& +h\left(\left(-0.71+0.087 b h-0.03 a h^{2}\right) f_{c}^{\prime 2}\right. \\
& +h\left(-0.2+0.055 b h-0.02 a h^{2}-0.003 a b h^{3}\right. \\
& \left.-0.0007 a^{2} h^{4}\right) f_{c}^{\prime} E_{c}+h^{2}\left(-0.015-0.003 a h^{2}\right. \\
& +0.00005 b^{3} h^{3}-0.0002 a^{2} h^{4}-4.88 \times 10^{-6} a^{3} h^{3} \\
& +b^{2}\left(-0.001 h^{2}-0.00007 a h^{4}\right) \\
& \left.\left.\left.\left.+b\left(0.007 h+0.0009 a h^{3}+0.00003 a^{2} h^{5}\right)\right) E_{c}^{2}\right)\right)\right)
\end{aligned}
$$

A2:

$$
\begin{gathered}
\int_{-\frac{h}{2}}^{-\frac{h}{2}+c}\left[1.05 E_{c}\left(a z^{3}+b z^{2}+e z+f\right)\right. \\
-0.3325 E_{c}^{2} \frac{\left(a z^{3}+b z^{2}+e z+f\right)^{2}}{f_{c}^{\prime}}
\end{gathered}
$$$$
\left.+0.025 E_{c}^{3} \frac{\left(a z^{3}+b z^{2}+e z+f\right)^{3}}{f_{c}^{\prime 2}}\right]\left(z+\frac{h}{2}-c\right) d z
$$$$
=\frac{1}{{f_{c}^{\prime}}^{2}} E_{c}-0.0002 a^{3} c^{11} E_{c}^{2}+a^{2} c^{10}(-0.0008 b
$$$$
+0.00125 a h) E_{c}^{2}+a c^{9}\left(-0.01 b^{2}-0.031 a^{2} h^{2}\right.
$$$$
+a(-0.003+0.004 b h)) E_{c}^{2}
$$$$
+c^{3}\left(\left(-0.48+0.175 b h-0.13 a h^{2}\right) f_{c}^{\prime 2}\right.
$$$$
+\left(f\left(0.29-0.108 b h+0.08 a h^{2}\right)\right.
$$$$
+h\left(-0.4+0.22 b h-0.147 a h^{2}-0.027 b^{2} h^{2}\right.
$$ 
$\left.\left.+0.034 a b h^{3}-0.01 a^{2} h^{4}\right)\right) f_{c}^{\prime} E_{c}$

$+\left(f^{2}\left(-0.034+0.0125 b h-0.0094 a h^{2}\right)\right.$

$+f h\left(0.092-0.051 b h+0.034 a h^{2}+0.006 b^{2} h^{2}\right.$

$\left.-0.0078 a b h^{3}+0.002 a^{2} h^{4}\right)+h^{2}(-0.063$

$-0.029 a h^{2}+0.0008 b^{3} h^{3}-0.004 a^{2} h^{4}$

$-0.0001 a^{3} h^{6}+b^{2}\left(-0.01 h^{2}-0.0014 a h^{4}\right)$

$\left.\left.\left.+b\left(0.046 h+0.013 a h^{3}+0.0008 a^{2} h^{5}\right)\right)\right) E_{c}^{2}\right)$

$+c^{8} E_{c}\left(-0.00045 b^{3} E_{c}+0.005 a^{3} h^{3} E_{c}\right.$

$+a b(-0.0073+0.005 b h) E_{c}+a^{2}\left(0.006 f_{c}^{\prime}\right.$

$\left.\left.-0.001 f E_{c}+h(0.013-0.009 b h) E_{c}\right)\right)$

$+c^{2}\left(-0.0125 f^{3} E_{c}^{2}+f^{2} E_{c}\left(0.1625 f_{c}^{\prime}\right.\right.$

$+h\left(0.05-0.009 b h+0.005 a h^{2}\right) E_{c}$

$+f\left(-0.525 f_{c}^{\prime 2}+h(-0.44+0.081 b h\right.$

$\left.-0.041 a h^{2}\right) f_{c}^{\prime} E_{c}+h^{2}(-0.07+0.025 b h$

$-0.013 a h^{2}-0.002 b^{2} h^{2}+0.002 a b h^{3}$

$\left.\left.-0.0006 a^{2} h^{4}\right) E_{c}^{2}\right)+h((0.71-0.13 b h$

$\left.+0.065 a h^{2}\right) f_{c}^{\prime 2}+h\left(0.3-0.11 b h+0.055 a h^{2}\right.$

$\left.+0.01 b^{2} h^{2}-0.01 a b h^{3}+0.003 a^{2} h^{4}\right) f_{c}^{\prime} E_{c}$

$+h^{2}\left(0.03+0.009 a h^{2}-0.0002 b^{3} h^{3}+0.0008 a^{2} h^{4}\right)$

$\left.\left.\left.+b\left(-0.017 h-0.003 a h^{3}-0.0002 a^{2} h^{5}\right)\right) E_{c}^{2}\right)\right)$ $+c^{6} E_{c}\left(0.003 a^{3} h^{5} E_{c}+a^{2} h^{2}\left(0.04 f_{c}^{\prime}-0.009 f E_{c}\right.\right.$

$\left.+h(0.03-0.01 b h) E_{c}\right)+a\left((0.06-0.06 b h) f_{c}^{\prime}\right.$

$+f(-0.014+0.0125 b h) E_{c}+h(0.046-0.05 b h$

$\left.+0.01 b^{2} h^{2}\right) E_{c}+b\left(-0.018 E_{c}-0.003 b^{2} h^{2} E_{c}\right.$

$\left.\left.+b\left(0.01 f_{c}^{\prime}-0.0025 f E_{c}+0.017 h E_{c}\right)\right)\right)$

$+c^{7} E_{c}\left(0.005 a^{3} h^{4} E_{c}+b^{2}(-0.004+0.002 b h) E_{c}\right.$

$+a^{2} h\left(-0.02 f_{c}^{\prime}+0.005 f E_{c}+h(-0.026+0.125 b h) E_{c}\right)$

$+a\left(-0.013 E_{c}-0.009 b^{2} h^{2} E_{c}+b\left(0.015 f_{c}^{\prime}\right.\right.$

$\left.\left.\left.-0.004 f E_{c}+0.03 h E_{c}\right)\right)\right)+c^{5}\left(-0.002 a^{3} h^{6} E_{c}^{2}\right.$

$\left.+a^{2} h^{3} E_{c}\left(-0.04 f_{c}^{\prime}+0.009 f E_{c}\right)\right)$

$+h(-0.02+0.007 b h) E_{c}+a\left(-0.05 f_{c}^{\prime 2}\right.$

$+(0.0325 f+h(-0.18+0.08 b h)) f_{c}^{\prime} E_{c}$

$+\left(-0.004 f^{2}+f h(0.04-0.019 b h)\right.$

$\left.+h^{2}\left(-0.07+0.05 b h-0.008 b^{2} h^{2}\right)\right) E_{c}^{2}$

$+E_{c}\left(-0.025 E_{c}+0.003 b^{3} h^{3} E_{c}\right.$

$+b^{2} h\left(-0.0325 f_{c}^{\prime}+0.0075 f E_{c}-0.025 h E_{c}\right)$

$\left.\left.+b\left(0.088 f_{c}^{\prime}-0.02 f E_{c}+0.055 h E_{c}\right)\right)\right)$

$+c^{4}\left(-0.002 b^{3} h^{4} E_{c}^{2}+0.0006 a^{3} h^{7} E_{c}^{2}\right.$

$+a^{2} h^{4} E_{c}\left(0.025 f_{c}^{\prime}-0.006 f E_{c}+0.01 h E_{c}\right)$

$+E_{c}\left(0.2 f_{c}^{\prime}-0.04 f E_{c}+0.06 h E_{c}\right)$ 


$$
\begin{aligned}
& +b^{2} h^{2} E_{c}\left(0.04 f_{c}^{\prime}+(-0.009 f+0.02 h\right. \\
& \left.+0.004 a h^{3}\right) E_{c}+b\left(-0.09 f_{c}^{\prime 2}+(0.054 f\right. \\
& \left.-0.22 h-0.068 a h^{3}\right) f_{c}^{\prime} E_{c}+\left(-0.006 f^{2}\right. \\
& +0.051 f h-0.07 h^{2}+0.016 a f h^{3} \\
& \left.\left.-0.032 a h^{4}-0.003 a^{2} h^{6}\right) E_{c}^{2}\right)+a h\left(0.13 f_{c}^{\prime 2}\right. \\
& \left.\left.\left.+\left(0.009 f^{2}-0.05 f h+0.058 h^{2}\right) E_{c}^{2}\right)\right)\right)
\end{aligned}
$$

\section{Biographies}

Mohsen Ghabdian is a $\mathrm{PhD}$ candidate in Structural Engineering at K.N. Toosi University of Technology. He received $\mathrm{BSc}$ and $\mathrm{MSc}$ in Civil Engineering at Sharif University in 2001 and 2006, respectively. He is engaged in several consulting projects including the industrial concrete structures in Iran. His research activities are focused on nonlinear structural analysis, time-dependent materials analysis, and nonlinear finite element method.

Seyed Bahram Beheshti Aval is an Associate Professor of Structural Engineering at K.N. Toosi University of Technology. He received his $\mathrm{PhD}$ in
Civil Engineering from Sharif University of Technology in 2000. He was the recipient of the post-doctoral North Carolina State University (NCSU) fellowship in 2001. He participated in several research activities within NSF and private sectors. He serves in various technical committees and is member to the editorial board of two international scientific journals in the field of civil engineering. He has taught courses on system identification, structural dynamics, and structural reliability analysis for several years. He received teaching awards in 2012. He advised more than $20 \mathrm{MSc}$ students and $7 \mathrm{PhD}$ students in the fields of earthquake engineering and structural dynamics. He is the author and co-author of more than 80 technical papers. He has been the Research Deputy of Civil Engineering Faculty for 6 years. He is the author of two books entitled "Seismic Rehabilitation of Existing Buildings, Theory and Application" and "Energy Principles and Vibrational Methods in Finite Element Analysis" in Persian.

Abolhassan Vafai is a Professor of Civil Engineering at Sharif University of Technology. He has authored/coauthored numerous papers in different fields of Engineering such as applied mechanics, biomechanics, and structural engineering (steel, concrete, timber, and offshore structures). He has also been active in the area of higher education and has delivered lectures and published papers on challenges of higher education, the future of science and technology, and human resources development. 